\title{
Duyarlı Sevgi
}

\section{Compassionate Love}

\author{
(iD) Yıldırım Gene(1), (iD Sefa Bulut(2) \\ (1)Istanbul Sabahattin Zaim Üniversitesi, Türkiye \\ (2)ibn Haldun Üniversitesi, Türkiye \\ (1)yildirimgene@gmail.com, (2)sefa.bulut@ihu.edu.tr
}

Öz: Geçtiğimiz otuz yıl içerisinde sevgi üzerine birçok araştırma yapılmıştır. Bu araştırmalar sevgiyi tanımlamaya, işlevsel hale getirmeye çalışış ve çeşitli değişkenlerle ilişkilerini incelemiştir. Yapılan çalışmaların çoğunluğu romantik sevgi üzerine odaklanmıştır. Aile, arkadaş gibi yakın çevre ile bütün insanlığa karşı duyulan sevgi genellikle bir inceleme konusu olmamıştır. Duyarlı sevgi kavramı diğerlerinin iyiliğine odaklanan özel bir sevgi türüdür. Yakın ya da uzak tüm insanlara karşı duyulan, ilgi, önemseme, yardım etme, fedakarlık gibi öğeleri içerisinde barından geniş bir kavramdır. Duyarlı sevgi empati, fedakarlık, merhametli olmak gibi kavramlara indirgenemez. Romantik sevgiden faklıdır, özgecil sevgiden ise daha kapsamlıdır. Duyarlı sevgi tüm insanlığı kapsar ve devamlılık gösterir. Olumlu sosyal davranışlara katkı sağlayan bir sevgi türü olduğu için araştırmacılar tarafından sevginin önemli bir çeşidi olarak görülmüştür. Bu çalışmada duyarlı sevgi kavramı açıklanmaya çalışılacaktır.

Anahtar Kelimeler: Sevgi, Duyarlı Sevgi

Abstract: A lot of research has been done on love over the past thirty years. These studies have tried to define love, make it functional and examine its relationships with variables. The majority of studies have focused on romantic love. Love for close friends such as family, friends and all humanity has not been a subject of study in general. The concept of compassionate love is a special type of love that focuses on the well-being of others. It is a broad concept within its elements such as interest, caring, helping and sacrifice towards all people, close or distant. Compassionate love cannot be reduced to concepts such as empathy, altruism, compassion. It is different from romantic love and more extensive than altruistic love. Compassionate love includes all humanity and shows continuity. Since it is a type of love that contributes to positive social behavior, it has been seen as an important type of love by researchers. In this study, the concept of compassionate love will be explained.

Keywords: Love, Compassionate Love

ORC-ID: Y. Gene 0000-0002-1440-8432; S. Bulut 0000-0002-2622-4390 


\section{Giriş}

Son zamanlarda Doğu psikolojisi içerisindeki kavramların bilim dünyasında ilgi görmeye başlamasıyla merhamet, affedicilik, fedakarlık gibi konularda araştırmalar artmıştır. Kişiliğin olumlu yönüne odaklanılmasıyla bu kavramların ölçülmesi ve diğer kavramlarla ilişkisinin araştırılmasının yolu açılmıştır (Akdeniz ve Deniz, 2016: 57).

Bu kavramlardan biri olan "Duyarlı Sevgi" öncelikle ilişkilerde deneyimlenen sevgi türlerinden biri olarak tarif edilmiştir. Fakat romantik sevgi çalışmalarının gölgesinde kalmıştır (Fehr, Harasymchuk ve Sprecher, 2014: 575). Bütün insanlar için hissedilen sevgi araştırmacılar tarafından gözden kaçırılmıştır (Sprecher ve Fehr, 2005: 629).

Sosyal destek, yakın ilişkiler alanında önemli bir araştırma alanı olmasına rağmen odak noktası destek sağlayıcıdan çok destek alıcısı olmuştur. İnsanları başkalarına yardım etmeye motive eden şeyin ne olduğu bilinmemektedir. Başkaları için deneyimlenen duyarlı sevginin hem yakınlara hem de yabancılara yardım etmek için güçlü bir neden olabileceği düşünülmektedir. İnsanların ilişki içerisinde oldukları insanların gereksinimlerine duyarlı olduklarında daha iyi hissetmeleri beklenmektedir (Sprecher ve Fehr, 2005: 631). Ayrıca çevresine yardımda bulunan kişilerin özsaygısı artmaktadır (Caprara ve Steca, 2005: 9). Duyarlı sevginin yakın ya da uzak tüm insanlara destek olmaya yönlendiren etkili bir motivasyon kaynağı olduğu düşünülmektedir (Fehr ve Sprecher, 2009: 343).

Araştırmalar destek amacıyla fedakarlığın ve başkalarını düşünmenin iyi hissetme ve uzun yaşamla ilişkili olduğunu ortaya koymuştur (Post, 2005: 72). Öte yandan başka insanlar tarafından kendilerine hissedilen duyarlı sevginin farkında olmayan insanlar bunu fark ettiklerinde olumlu kişilik özellikleri ortaya çıkmakta ve öz saygıları artmaktadır (Sedikides, Oliver ve Campell, 1994: 20). Tüm insanlara karşı hissedilen duyarlı sevgi olumlu toplumsal davranışların ortaya çıkmasına vesile olduğundan önemli hale gelmektedir (Sprecher ve Fehr, 2005: 631).

İnsanlık çevresel sürdürülebilirlik ve dünya barışı gibi birçok zorlukla karşı karşıyadır. Bu zorlukların başarılı bir şekilde karşılanması büyük ölçüde kişilerarası, gruplar arası ve uluslararası ilişkilere dayanmaktadır. Duyarlı sevginin toplum yanlısı gücünün bu ilişki düzeylerine katkıda bulunabileceği düşünülmektedir (Perlman ve Aragon, 2009: 451). Aynı şekilde sosyal bilimciler de duyarlı sevgiye dikkat çekmekte ve topluma büyük sosyal fayda sağlayabileceğini savunmaktadır (Fehr ve Sprecher, 2009: 343). 


\section{Sevgi}

Sevgi kavramı niceliği ve niteliği açısından sonsuz bir evrene benzetilmektedir (Sorokin, 2005: 229). Sevginin fiziksel, psikolojik, biyolojik, din ve ahlak gibi pek çok yönünden söz edilebilir (Peck, 2009: 81). Sevginin bu çok yönlü girift yapısı tanımlanması güçlüğünü de beraberinde getirmiştir. Birçok tanımının yanında sevgi genellikle başkalarına yönelik bir duygu olarak bireyin kendisi ve diğerlerinin iyi oluşunu desteklemek amacıyla benliğini genişletme isteği olarak tarif edilmiştir (Öner, 2017: 5).

Sevgi türleri ile ilgili yapılan çalışmalar içerisinde en kapsamlı olanı Hendrick ve Hendrick'e ait eserdir (1986). Sevgi türleri kuramına göre altı tür sevgiden söz edilmektedir. Bunlar romantik sevgi (eros), oyuna benzetilen sevgi (/udus), arkadaşça sevgi (storge), mantıklı sevgi (pragma), sahiplenici sevgi (mania) ve verici sevgi'dir (agape) (Hendrick ve Hendrick, 1986: 85).

Yakın zamanda yapılan bir çalışmada Berscheid (2010) dört aşamalı bir ayrımın teorik olarak en tutarlı gruplama olduğunu savunmuştur. Bunlar arkadaşça sevgi, romantik sevgi, yetişkin bağlanma sevgisi ve duyarlı sevgidir. Bu sevgi türlerinden ilk üçü etraflıca incelenmiştir. Duyarlı sevgi ise ilişki-bilim literatürüne görece yeni girmiştir ve az incelenmiştir (Reis, Maniaci ve Rogge, 2014: 651).

\section{Duyarlı Sevgi}

Tüm insanlığın iyi oluşuna odaklanan bir sevgi türü olan duyarlı sevgi yakın ya da uzak tüm insanlara duyulan yardım etme, önemseme, ilgi, şefkat gibi duygu ve düşünceler ile fedakarlık, empati gibi öğeleri de içinde barındıran kapsamlı bir kavramdır (Lazarus, 1991: 289; Eker, 2011: 41). Yakın ya da uzak tüm insanlar için alaka, sevecenlik, duyarlı olmayı içeren duygu ve düşünceler ile başkaları acı çektiğinde ve yardıma muhtaç olduğunu sezdiğinde yardım etme, anlama ve desteklemeye yönelik bir eğilim olarak tanımlanmıştır (Nickolas, 2009: 10). Diğerlerinin iyiliği için endişeyi vurgulayan fedakar ve şefkatli bir sevgi biçimidir (Reis, Maniaci ve Rogge, 2014: 651). Başkalarının iyi olmasına yoğunlaşan bir çeşit sevgi türüdür (Underwood, 2008: 3).

Batson ve Oleson'a (1991) göre tüm insanlığı kapsar ve süreklilik gösterir. Duyarlı sevgi kutsal sevgi, karşılıksız ya da fedakar sevgi olarak da tanımlanmaktadır (Underwood, 2009: 3). Romantik sevgi ve anne sevgisi gibi diğer sevgi türlerinden, her türlü ilişki ve ortamda deneyimlenebilen evrensel bir sevgi türü olmasıyla ayırt edilebilir (Fehr, Sprecher ve Underwood, 2009: 11). 
Lazarus'un tanımına göre diğer insanların acı çekmesinden duygulanma ve yardım etme isteğidir (Sprecher ve Fehr, 2005: 630). Duyarlı sevginin içeriğinde yardımseverlik, empati, sempati, fedakarlık gibi özellikler vardır (Fehr ve Sprecher, 2009: 39). Empati ve sempati kavramlarıyla alakalı olmasına rağmen birbirlerinden farklı süreçlerdir (Nickolas, 2009: 212). Sempati acı duyan ya da sıkıntı çeken kişiyle aynı hissetmek değil ona karşı üzüntü ve ilgi ile duygusal bir karşılık vermektir (Eisenberg, 2000: 678).

Duyarlı sevgi empatiye indirgenmemelidir (Post, 2003: 46). Duyarlı sevgi empatiden farklı bir terimdir. Toplumun tümünü kapsayıp aynı zamanda süreklilik göstermektedir. Empati ile yüksek düzeyde değil orta düzeyde ilişkili olup ikisinin ayrı kavramlar olduğu bulunmuştur. Empati bir başkasının duygusal durumunu paylaşmaya odaklanırken duyarlı sevgi kendi başına başka bir duygudur. Kısmen Lazarus' un (1991) ayrımına dayanarak duyarlı sevginin şefkat, empati ve kendini feda etme gibi davranışsal eğilimleri içerdiği için daha kapsamlı bir terim olduğu öne sürülmektedir. Diğer taraftan duyarlı sevgi daha kalıcı olabilir. Çünkü deneyimi ortaya çıkaran belirli bir hedeften bağımsız olarak deneyimlenmesi muhtemeldir. Oysa empati özellikle birisinin acısına yanıt olarak ortaya çıkmaktadır (Sprecher ve Fehr, 2005: 630).

Duyarlı sevgi birçok inanışta iyi kabul edilen davranışların içeriğinde var olan sevgidir. İçüdüsel veya zorunlu olmayıp karşılık bekleyen bir sevgi de değildir (Underwood: 2009: 5). Merhamet ile ilişsili yapılar olmasına rağmen birbirinden farklıdır (Akdeniz ve Deniz, 2016: 57).

Duyarlı sevgide diğerlerine kesinlikle acıma duygusuyla yönelimde bulunulmaz. Sonsuz bir saygı duymayı ve değer vermeyi gerekli kılar. İçten ve samimi bir yaklaşımda bulunulur (Underwood, 2009: 7). Duyarlı sevginin açıklayıcı iki özelliği sezgi ve uygun motivasyondur. Sezgi bireyin iyi oluşunu artırmak için doğru olanı idrak etme olarak tanımlanırken, uygun motivasyon diğerlerinin iyi oluşuna odaklanmak olarak açıklanmaktadır (Underwood, 2008: 7). Sprecher ve Fehr (2005) bunu diğerinin iyi oluşuna odaklanmak ve başkasının iyi olması için ne yapılacağını kestirmek olarak açıklamaktadır. Bu sevgiyi hisseden kişilerde kendine saygının arttığı, yapıcı ilişkiler kurduğu, sağlıklarının arttığı ve iyi ruh halini destekleyici etkileri olduğu tespit edilmiştir (Fehr ve Specher, 2008: 28).

Duyarlı sevginin beş unsuru vardır. Bunlar değer verme, seçme hakkı, açık sözlü olma, tam bilişsel kavrayış ve durumların duygusal anlaşılmasıdır (Underwood, 2002'dan akt. Virat, 2020: 4). Underwood'un bu tanımı duyarlı sevgiyi veren kişinin bakış açısından 
olsa da bu sevgiyi alan kişinin bakış açısını da değerlendirerek şu tanımlamayı yapıyor; gerçekte kim olduğun için sevilmek, hatalarını bilen biri tarafından sevilmek, sizi tam anlamıyla yaşatan bir şekilde sevilmektir. Kısaca özetlemek gerekirse Underwood duyarlı sevgiyi "kendini başkasının iyiliği için vermek" olarak tanımlıyor (Perlman ve Aragon, 2009: 435-436).

Duyarlı sevgi yakınlara ya da yabancılara yani tüm insanlığa karşı bir tutumdur. Özellikle diğerleri acı çekiyor olduğunda ve ihtiyaç duyduklarında önem verme, ilgi, hassasiyet, onları destekleme yardım etme ve anlamaya yönelik bir yönelimle odaklanılan duyguları, bilişleri ve davranışları içerir. Durumsal ve ilişkisel bağlamlardan ve geçici ruh hallerinden etkilenen dalgalı bir durum olmasının yanı sıra muhtemelen kalıcı bir tutum veya eğilimdir (Sprecher ve Fehr, 2005: 630).

Diğer taraftan duyarlı sevgi diğerkamlıkla da aynı değildir. Ondan daha zengin bir kavramdır (Saunders, 2013: 5). Diğerkamlık tabii bir eğilimden, zorunluluktan ya da görev düşüncesinden yapılabilir. Duyarlı sevgi ise zorlama olmadan yapılan bilinçli bir davranış olmakla birlikte daha çok sevgi ihtiva etmektedir (Post, Underwood, Schloss ve Hurlbut, 2002: 74).

Yüzyıllar boyunca tüm değerli manevi ve ahlaki geleneklerde kolayca ifade edilen en evrensel iddia duyarlı sevgidir (Post, 2010: 38). Duyarlı sevginin olumlu bir ahlaki yönü vardır ve başkaları için davranışsal bir bağlılı̆ı ifade eder (Oman, 2011: 947). Tipolojilerin çoğu duyarlı sevgiyi öteki merkezli sevgi olarak içerir (Underwood, 2005' den akt. Virat, 2020: 4). Bu bağlamda duygusal ya da fiziksel bir bedel karşılığında sevilmek bireyde özel bir etki yaratabilir (Fehr, Sprecher ve Underwood, 2008: 3). Öte yandan duyarlı sevginin çocuk ebeveyn ilişkileri, romantik ilişkiler, liderlik, gönüllülük, gruplar arası iletişim ve profesyonel sağlık bakımı gibi çeşitli alanlarda olumlu etkileri vardır. Duyarlı sevgi artık ilişkisel mesleklerde toplum yanlısı davranışların önemli bir belirleyicisi olarak görülmektedir (Virat, 2020: 4).

\subsection{Yakınlara Karşı Duyarlı Sevgi}

Fehr ve Sprecher (2009) prototip teorisini kullanarak sevgi türlerini ve özelliklerini incelemiştir. Prototip araştırmalar göstermiştir ki "duyarlı sevgi", "koşulsuz sevgi", "sevgi verme" ve "özgecil (fedakar) sevgi" bireylerin sevgi tipolojilerinin bir parçası olarak ortaya çıkmaktadır. Güven, ilgi, yardım ve paylaşım çoğu sevgi türüyle ilişkilendirilebilir. Sevgi tarzları üzerine yapılan bu araştırmalar özellikle özgecil (fedakar) sevginin önemini vurgulamaktadır (Hendrick ve Hendrick, 1986; Lasswell ve 
Laswell, 1976; Lee, 1973). Alan yazına bakıldığında ise sadece birkaç teorik araştırmada yakın ilişkiler için duyarlı sevginin öneminden bahsedilmektedir (Sprecher ve Fehr, 2005: 3).

Yapılan çalışmalar fedakar sevginin uzun süreli ilişkilerde ve dindarlar arasında daha fazla deneyimlendiği göstermektedir (Hendrick ve Hendrick, 1992). Aşık olan kişiler aşık olmayanlara göre daha fazla duyarlı sevgi göstermektedir (Neto ve Wilks, 2017: 610). Bir araştırmada romantik ilişkilerin kalitesi ve istikrarında duyarlı sevginin önemli bir rol oynadığı bulunmuştur (Fehr, Harasymcuk ve Sprecher 2014, 593). Diğer bir araştırma çocuklu katılımcıların çocuğu olmayanlara göre daha yüksek duyarlı sevgi puanı aldığını söylemektedir (Mersin, İbrahim, Çağlar ve Akyol, 2020: 72).

Genellikle bireyler duyarlı sevgi alıcısı olduklarını en çok yakın çevrelerinde ilişki içerisinde oldukları kişiler sayesinde hissedebilmektedir. Bu şekilde alınan duyarlı sevgi fiziksel sağlık için de çok önemlidir (Ornish, 1999: 67). Örneğin bir eşin sevgisi barsak ülseri olma riskini düşürmektedir. Diğer bir bulguda ise her iki ebeveyninden düşük sıcaklık ve yakınlık bildiren kişilerin \%100'ünde orta yaş hastalık (kroner arter hastalığı, yüksek tansiyon, alkolizm, duodenum ülseri) tanıları görülmüştür (Ornish, 1999: 76). Son olarak tanışıklık olumlu ve nötr kişilere karşı sevgiyi artırmaktadır (Freedman, Sears ve Carlsmith, 2003: 204).

\subsection{Yabancılara ve İnsanlığa Karşı Duyarlı Sevgi}

Sevgi üzerine yapılan araştırmalara bakıldığında yabancılar, çevre bağları veya tüm insanlık için yaşanan sevginin pek araştırılmadığı görülmektedir. Oysa "insanlık için sevgi” psikoloji alanı çalışanlarının dışındakiler tarafından da görece iyi bir sevgi örneği olarak kabul edilmektedir (Fingerman, 2004: 185). İnsanlar genellikle başkaları tarafından kendilerine duyulan duyarlı sevginin farkında değildir. Bunun farkında olunduğunda bireylerin özsaygıları artmakta ve olumlu kişilik özellikleri ortaya çıkmaktadır (Sedikides, Oliver ve Campell, 1994: 16).

Alan yazına göre fedakarlık isteği, ahlaki muhakeme gücü ve empati yeteneği ile ilişkili bir olgudur. Bu kavramların hepsi duyarlı sevgi ile ilişkili karakter özellikleridir. Bu özelliklerin her biri bireydeki duyarlı sevgi düzeyinin gelişimini desteklemektedir (Dovido ve Penner, 2001' den akt. Sprecher ve Fehr, 2005: 630).

Fingerman (2004) yaptığı araştırmasında yabancılarda dahil olmak üzere çevresel bağlarla ilişkilerin bireyde insani gelişme ve mutluluğa katkısı olduğunu belirlemiştir 
(Fingerman, 2004: 204). Daha az şanslı olanlar da dahil olmak üzere diğer insanlara yönelik hissedilen duyarlı sevgi deneyimi onların iyi oluşlarının artmasına neden olmaktadır (Sprecher ve Fehr, 2005: 632). Ayrıca tüm insanlığa karşı hissedilen duyarlı sevgi ile maneviyat arasında da pozitif yönlü ilişki bulunmaktadır (Sprecher ve Fehr, 2005: 646).

\section{Tartışma ve Sonuç}

Duyarlı Sevgi kavramı esasında dini ve felsefi literatürde yüzyıllardır bulunan bir kavramdır. Ancak sosyal bilimciler için nispeten yeni bir terimdir (Perlman ve Aragon, 2009: 450). Örneğin Amerikan Psikoloji Derneği veritabanı Psycınfo'da yapılan bir taramada 2001 yılına kadar hiçbir psikolojik makalenin başlığında duyarlı sevgi teriminin kullanılmadığı belirlenmiştir (Fehr, Sprecher ve Underwood 2009: 434).

Duyarlı sevgiye son zamanlarda duyulan ilgi sosyal bilimciler tarafından Budist ve Doğu psikolojisinin sevgi içeren nezaket olarak şefkate odaklanmasında ve başkalarının acılarını hafifletme isteğinden esinlenerek merhamet üzerine çalışmalar yapılması ve bu çalışmaların genişletilmesine paralel olarak gelişmiştir (Fehr ve Sprecher, 2009: 344).

Tutkulu aşkı, bağlanma sevgisini anlamaya yönelik önemli araştırmalar yapılmasına karşın duyarlı sevgi hala anlaşılmaya çalışılan ve araştırılan bir kavramdır (Neto ve Wilks, 2017: 606).

Duyarlı sevginin ne olduğu ve nasıl tanımlanması gerektiği konusu uzmanlarca tartışılmaya devam eden bir konudur. Alan çalışanları ve meslekten olmayanlar farklı tanımlamalar yapmaktadır. Aslında bu bilgi sıradan insanların zihninde mevcuttur. Araştırmalar meslekten olmayan kişilerin duyarlı sevginin özellikleri hakkında zengin ve karmaşık bir bilgiye haiz olduklarını göstermektedir. Bunu onların iç görüleri ve deneyimleri sağlamaktadır (Fehr ve Sprecher, 2009: 362). Esasında aynen sevgi kavramı gibi klasik tanıma uygun olmayan doğal dil kavramlarından biridir (Fehr ve Sprecher, 2009: 361). Kompleks ve çok yönlü bir yapıdadır. İçeriğinde güdüleme, insanların farkında olma ve onlara yardım etme gibi nosyonları barındırmaktadır (Fehr ve Sprecher, 2009: 344).

Yapılan münferit araştırmalar duyarlı sevginin bir kavram olarak diğer kavramlarla ne şekilde ilişkili olduğunu gösterdiği gibi diğer yandan benzersiz bir tarafının olduğunu da ortaya koymaktadır. Kavramın özgünlüğünü ortaya koyan araştırmacılar bunun için gönüllülük, sağlık hizmetleri ve gruplar arası ilişkiler gibi değişik alanlardan duyarlı sevgi kavramını inceleyen araştırmalar yaptılar. Ve bu araştırmaları 2009 yılında 
Blackwell yayınevinden The Science Of Compassionate Love başlığıyla neşretmişlerdir (Perlman ve Aragon, 2009: 451).

Duyarlı sevgi üzerine yapılan çalışmaların ana hedeflerinden biri bireylerde ve toplumlarda nasıl teşvik edileceğidir. Bunun için duyarlı sevginin temel özelliklerini anlamak önemlidir (Underwood, 2002: 87). Duyarlı sevgi belirli bir amaç güdülmeden hissedilmektedir. Devamlı hissedilen içeriğinde ilgili ve duyarlı olmayı barındıran davranışa bağlı bir eğilimdir. Ayrıca başkalarıyla yüz yüze durumlarla sınırlı değildir (Sprecher ve Fehr, 2005: 630). Hem kişilik faktörlerine hem de durumsal faktörlere bağlıdır (Oman, 2011: 961). Duyarlı sevgi romantik aşkla aynı olmamakla beraber alışkanlık halinde duyulan fedakar sevgiden de daha zengindir (Underwood, 2008: 35). Affetme, empati, ilgi, özveri ve sosyal destek gibi duygulardan ayrılmaktadır (Saunders, 2013: 5). Şefkatten sadece acı çeken veya savunmasız insanlara yönelik olmaması bakımından da farklıdır (Oman, 2011: 947).

Duyarlı sevgi hakkında yapılan çalışmalar bize toplum yanlısı davranışları teşvik etmesi ve olumlu sosyal etkisi hakkında bilgi vermektedir. Örneğin, bir çalışmada öğretmenlerin öğrencilerine olan duyarlı sevgisinin öğretmen öğrenci ilişkisinin kalitesini öngördüğü sonucuna ulaşılmıştır. Bu da bize duyarlı sevginin öğretmen öğrenci ilişkisinin önemli bir belirleyicisi olabileceğini göstermektedir (Virat, 2020: 911). Bir başka çalışmada liderlerin duyarlı sevgi düzeyleri ile hizmetkar liderlik davranışı arasında pozitif ilişki bulunmuştur. Araştırma sonucuna göre duyarlı sevgi sergileyen bireylerin değer odaklı kararlar alma ve olumlu toplumsal etki bırakma açısından üyesi oldukları kuruluşun sürdürülebilirliğini teşvik eden iyi hizmetkar liderler olma potansiyeline sahip olduğunu göstermektedir (Brouns, Externbrink ve Aledo, 2020: 7).

Önyargıyı azaltmak sosyal psikolojinin uzun süredir devam eden bir amacı olmuştur. On yıllardır yürütülen araştırmaların çoğunun amacı farklı sosyal grupların üyeleri arasındaki olumsuzluğu azaltmaktır. Önyargı ile duyarlı sevgi arasındaki ilişki hakkında yapılan bir çalışmada duyarlı sevgi düzeyi yüksek insanların göçmenler de dahil diğer gruplara karşı daha olumlu tutum içerisinde olduğu bulunmuştur. Bu kişiler aynı zamanda duyarlı sevgi düzeyi düşük olanlara göre başkalarına karşı daha az önyargı ifade etmiştir. Dolayısıyla duyarlı sevginin, önyargıyı azaltmanın olumlu bir yolu olduğunu vaat ettiği sonucuna ulaşılmıştır (Sinclair, Fehr, Wang ve Regehr, 2016: 176180). 
Dünya sağlık örgütü tarafından yapılan çok kültürlü bir çalışmada "duyarlı sevgi" terimi son zamanların en iyi uzlaşmacı ifadesi olarak öne çıkmıştır (Underwood, 2008: 9).

Duyarlı sevginin ebeveyn çocuk ilişkileri (Miller ve ark., 2015; Volling, Kolak ve Kennedy, 2009), romantik ilişkiler (Collins ve ark., 2014; Jeffries, 2006; Neff ve Karney, 2009), gönüllülük (Omoto, Malsch ve Barraza, 2009), liderlik (Van Dierendonck ve Patterson, 2015), gruplar arası iletişim (Sinclair ve ark., 2016) ve profesyonel sağlık bakımı (Graber ve Mitcham, 2009; Willer, 2014) gibi çeşitli bağlamlarda olumlu etkileri vardır (Virat, 2020: 4).

Sonuç olarak duyarlı sevgi kalıcı ve kapsayıcı bir yapı olarak yabancılara yönelik gönüllülük ve yakınlara karşı sosyal destek de dahil olmak üzere toplum yanlısı davranışlara katkıda bulunabilir (Sprecher ve Fehr, 2005: 631).

\section{Referanslar}

Akdeniz, S. ve Deniz, M. E. (2016). Merhamet Ölçeği'nin Türkçeye uyarlanması: Geçerlik ve güvenirlik çalışması. The Journal of Happiness \& Well - Being, 4(1), 50-61.

Batson, C. D. \& Oleson K. C. (1991). Current status of the empathy-altruism hypothesis. Review of Personality And Social Psychology, 12, 62-85.

Berscheid, E. (2010). Love in the fourth dimension. Annual Review of Psychology 67(1), 1-25. DOI: 10.1146/annurev.psych.093008.100318

Brouns, T., Externbrink, K. \& Aledo, P. S.B. (2020). Leadership beyond narcissism: On the role of compassionate love as individual antecedent of servant leadership. Administrative Sciences, 10(20), 1-10. DOI: $10.3390 /$ admsci 10020020

Caprara, G. V. \& Steca, P. (2005). Affective and social self-regulatory efficacy beliefs as determinants of positive thinking and happiness. European Psychologist, 10(4), 1-12.

DOI : 10.1027/1016-9040.10.4.xxx

Collins, N. L., Kane, H.S., Metz, M.A., Cleveland, C., Khan, C., Winczewski, L., Bowen, J., \& Prok, T. (2014). Psychological, physiological, and behavioral responses to a partner in need: The role of compassionate love. Journal of Social and Personal Relationships, 37(5), 601-629. DOI: $10.1177 / 0265407514529069$

Dovidio, J. F. \& Penner, L. A. (2001). Helping and altruism. Brewer, M. \& Hewstone, M. (Eds.). Blackwell international handbook of social psychology: Interpersona processes içinde (162195. ss.). Cambridge, MA: Blackwell.

Eisenberg, N. (2000). Empathy and sempathy. Lewis, W. \& Halvin-Jones, J. M. (Eds.). Handbook of emotions içinde (677-691. ss.). New York: The Guilford Press.

Eker, H. (2011). Üniversite öğrencilerinin öz-duyarlılık ve duyarlı sevgi düzeylerinin ebeveyn tutumları açısından incelenmesi. Sakarya Üniversitesi, Eğitim Bilimleri Enstitüsü, Sakarya. 
Fehr, B., Harasymchuk, C. \& Sprecher, S. (2014). Compassionate love in romantic relationships: A review and some new finding. Sage Journals, 37(5), 575-600. DOI: $10.1177 / 0265407514533768$

Fehr, B. \& Sprecher, S. (2008). Compassionate love: Conceptual, measurement, and relational issues. Fehr, B., Sprecher, S. \& Underwood, L. G. (Eds.), The science of compassionate love: Theory, research, and applications içinde (27-52. ss.). Malden M.A.: Wiley-Blackwell.

Fehr, B. \& Sprecher, S. (2009). Prototype analysis of the concept of compassionate love. Journal of The International Association For Relationship Research, 16(3), 343-364. DOI: $10.1111 /$ j.1475-6811.2009.01227.x

Fehr, B., Sprecher, S. \& Underwood, L. G. (2008). The science of compassionate love: Theory, research, and applications. Malden, M.A.: Blackwell.

Fehr, B., Sprecher, S. \& Underwood, L. G. (2009). Compassionate love: Theory, research, and applications. Malden, M.A.: Wiley-Blackwell.

Fingerman, K. L. (2004). The consequential stranger: Peripheral relationships across the life span. Lang, F. R. \& Fingerman, K. L. (Eds.). Growing together: Personal relationships across the lifespan içinde (183-209. ss.). New York: Cambridge University Press.

Freedman, J. L., Sears, D. O. \& Carlsmith, J.M. (2003). Introduction to social psychology. (Çev. Ali Dönmez). Ankara: İmge Kitabevi.

Graber, D. R. \& Mitcham, M. D. (2009). Compassionate clinicians: Exemplary care in hospital settings. In the science of compassionate love: Theory, research,and applications, (345-372. ss.)., Malden: Blackwell.

Hendrick, C. \& Hendrick, S. (1986). A theory and method of love. Journal of Personality and Social Psychology, 50 (2), 392-402.

Hendrick, S. S. \& Hendrick, C. (1992). Romantic love. Sage Publications Inc.

Jeffries, V. (2006). Religiosity, benevolent love, and long-lasting marriages. Humboldt Journal of Social Relations, 30(1), 77-106.

Lasswell, T. E. \& Lasswell, M. E. (1976). I love you but I'm not in love with you. Journal of Marriage and Family Counseling, 38, 211-224. DOI: 10.1111/j.17520606.1976.tb00413.x

Lazarus, R. S. (1991). Emotion and adaptation. New York: Oxford University Press.

Lee, J. A. (1973). The colors of love: An exploration of the ways of loving. Don Mills, ON: New Press.

Mersin, S., İbrahimoğlu, Ö., Çağlar, M. ve Akyol, E. (2020). Compassionate love, burnout and professional commitment in nurses. Journal of Nursing Management, 28(1), 72-81. DOI: $10.1111 /$ jonm. 12892

Miller, J. G., Kahle, S., Lopez, M. \& Hastings, P. D. (2015). Compassionate love buffers stressreactive mothers from fight-or-flight parenting. Developmental Psychology, 51(1), 36-43. DOI: $10.1037 / \mathrm{a} 0038236$

Neff, L. A. \& Karney, B. R. (2009). Compassionate love in early marriage. Fehr, B.,Sprecher, S. \& Underwood (Eds.). The science of compassionate love: Theory, research, and applications içinde (201-222. ss.). L. Malden: Blackwell. 
Neto, F. \& Wilks, D. C. (2017). Compassionate love for a romantic partner across the adult life span. Europe's Journal of Psychology, 13(4), 606-617. DOI: 10.5964/ejop.v13i4.1204

Nickolas, M. A. (2009). Fostering social support and compassionate love in the greek orthodox church through small groups. (Unpublished doctoral dissertation). The Boston University, Boston.

Oman, D. (2011). Compassionate love: Accomplishments and challenges in an emerging scientific / spiritual research field. Mental Health Religion and Culture, 14(9), 945-981. DOI: 10.1080/13674676.2010.541430

Omoto, A. M., Malsch, A. M. \& Barraza, J. A. (2009). Compassionate acts: Motivations for and correlates of volunteerism among older adults. Fehr, B., Sprecher, S. \& Underwood, L. (Eds.). The science of compassionate love: Theory, research, and applications içinde (257-282. ss.). Malden: Blackwell.

Ornish, D. (1999). Love and survival: The scientific basis for the healing power of intimacy. New York: Perennial Currents.

Öner, Ç. (2017). Spor bilimleri fakülteleri antrenörlük öğrencilerinin otantik liderliklerinin yaşam boyu öğrenme eğilimleri ve duyarlı sevgi becerileri açısından incelenmesi. Spor Bilimleri Araştırmaları Dergisi, 2(2), 1-20. DOI: 10.25307 /jssr.328103

Peck, M. S. (2009). Az seçilen yol: Sevginin, geleneksel değerlerin ve ruhsal tekâmülün psikolojisine yeni bir bakış (Çev. R. Özer). İstanbul: Akaşa Yayınları.

Perlman D. \& Aragon R. S. (2009). Compassionate love: Concluding reflections. Fehr, B., Sprecher, S. \& Underwood, L. G. (Eds.). The science of compassionate love: Theory, research, and applications içinde, (433-452. Ss.). Blackwell Publishing.

Post, S. G. (2003). Unlimited love: Altruism, compassion, and service. Philadelphia And London: Templeton Foundation Press.

Post, S. G. (2005). Altruism, happiness, and health: It's good to be good. International Journal of Behavioral Medicine, 12, 66-77.

Post, S. G. (2010). Humanism, posthumanism, and compassionate love. Technology In Society, 32(1), 35-39. DOI: 10.1016/j.techsoc.2009.12.007

Post, S. G., Underwood, L. G., Schloss, J. P. \& Hurlbut, W. B. (2002). Altruism and altruistic love: Science, philosophy, and religion in dialogue. New York: Oxford University Press.

Rauer, A. J. Sabey, A. \& Jensen, J. F. (2014). Growing old together: Compassionate love and health in older adulthood. Journal of Social and Personal Relationships, 37(5), 677-696. DOI: $10.1177 / 0265407513503596$

Reis, H. T., Maniaci, M. R. \& Rogge, R. D. (2014). The expression of compassionate love in everyday compassionate acts. Journal of Social And Personal Relationships, 31(5), 651-676. DOI: $10.1177 / 0265407513507214$

Saunders, W. D. (2013). Growing compassionate love in communities. Los Angeles: YMCA of Metropolitan.

Sedikides, C., Oliver, M. B. \& Campbell, W. K. (1994). Perceived benefits and costs of romantic relationships for women and men: Implications for exchange theory. Personal Relationships, 1, 5-21. DOI: $10.1111 /$ j.1475-6811.1994.tb00052.x 
Sinclair, L., Fehr, B., Wang, W. \& Regehr, E. (2016). The relation between compassionate love and prejudice: The mediating role of inclusion of out-group members in the self. Social Psychological and Personality Science, 72): 176-183. DOI: 10.1177/1948550615609736

Sorokin, P. A. (2005). Özgeci Sevgi. Kirch A. (Eds.) Aşkın Anatomisi içinde (Çev. M. Harmancı) (221-233. ss.). İstanbul: Say Yayınları.

Sprecher, S. \& Fehr, B. (2005). Compassionate love for close others and humanity. Journal of Social and Personal Relationships, 22(5), 629-651. DOI: 10.1177/0265407505056439

Sprecher, S. \& Fehr, B. (2011). Dispositional attachment and relationship-specific attachment as predictors of compassionate love for a partner. Journal of Social And Personal Relationships, 28(4), 558-574. DOI: 10.1177/0265407510386190

Sprecher, S., Zimmerman, C. \& Abrahams, E. M. (2010). Choosing compassionate strategies to end a relationship: Effects of compassionate love for partner and the reason for the breakup. Social Psychology, 47(2), 66-75. DOI: 10.1027/1864-9335/a000010

Underwood, L. G. (2002). The human experience of compassionate love. Post, S. G., Underwood, L. G., Schloss, J. \& Hurlbut, W. B. (Eds.), Altruism and altruistic love içinde (72-88. ss.). Oxford: Oxford University Press.

Underwood, L. G., (2005). Interviews with trappist monks as a contribution to research methodology in the investigation of compassionate love. Journal for The Theory of Social Behaviour, 35(3), 285-302.

Underwood, L. G. (2008). Compassionate love: A framework for research. Fehr, B., Sprecher, S. \& Underwood, L. G. (Eds.), The science of compassionate love: Theory, research, and applications içinde (3-25. ss.). Malden, M.A.: Wiley-Blackwell.

Underwood, L. G. (2009). Compassionate love: A framework for research. Malden, M. A.: WileyBlackwell.

van Dierendonck, D. \& Patterson, K. (2015). Compassionate love as a cornerstone of servant leadership: An integration of previous the orizing and research. Journal of Business Ethics, $128(1), 119-131$.

Virat, M. (2020). Teachers' compassionate love for students: a possible determinant of teacherstudent relationships with adolescents and a mediator between teachers' perceived support from coworkers and teacher-student relationships. Educational Studies, 46(1), 1-19. DOI: 10.1080/03055698.2020.1751083

Volling, B. L., Kolak, A. M. \& Kennedy, D. E. (2009). Empathy and compassionate love in early childhood : Development and family influence. Fehr, B., Sprecher, S. \& Underwood, L. (Eds.). The Science of Compassionate Love: Theory, Research, and Applications içinde (161-200. ss.). Malden: Blackwell.

Willer, E. K. (2014). Health-care provider compassionate love and women's infertility stressors. Communication Monographs, 81(4), 407-438. DOI: 10.1080/03637751.2014.940591 